\title{
EVALUASI PELAT LANTAI BETON PRACETAK (PRECAST) KE PELAT LANTAI BETON KONVENSIONAL PADA GEDUNG RUSUNAWA SUKABUMI
}

\author{
${ }^{1}$ Yudi Sekaryadi, ${ }^{2}$ Asep Hermawan \\ Program Studi Teknik Sipil Fakultas Teknik Universitas Suryakancana \\ yudisekaryadi65@gmail.com
}

\begin{abstract}
Abstrak
Pelat beton bertulang merupakan bagian stuktur bangunan yang menahan permukaan (beban vertical),biasanya memiliki arah horizontal,dengan permukaan atas dan bawahnya sejajar.pelat dapat di tumpu oleh balok bertulang.dinding pasangan batu atau beton bertulang,batang batang stuktur baja,di tumpu secara langsung oleh kolom,atau tertumpu secara menerus oleh tanah.pelat dapat di tumpu biasanya pada dua sisi yang berlawanan saja.yang biasanya di sebut pelat satu arah,(one way).pelat juga dapat di tumpu pada ke empat sisi yang biasanya di sebut pelat dua arah (two way) pada kondisi ini beban lantai di pikul dalam kedua arah oleh ke empat balok pendukung seluruh panel.apabila perbandingan panel pelat lebih besar atau sama dengan 2 maka sebagian besar beban akan di tahan oleh pelat dalam arah pendek terhadap balok-balok penunjang dan sebagainya mengakibatkan di proleh aksi pelat satu arah, walaupun ke empat sisinya di beri tumpuan.

Penelitian ini di tunjukan untuk meninjau pelat lantai yang menggunakan pelat lantai precast dengan pelat lantai konvensional .dari hasil Analisa pelat lantai yang mengunakan pelat precastlebih evesien dalam pelaksanaan pekerjaan sebuah gedung dan dari segi kekeuatan beton precast dan beton konvensional sama kuat Cuma proses pekerjaan lebih cepat dan evisien waktu pada saat pengerjaan pelat lantai di lapangan.
\end{abstract}

Kata Kunci : evaluasi, pelat lantai, precast, beton

\section{PENDAhUluan}

Pelat lantai merupakan salah satu dari komponen stuktur kontruksi baik pada gedung maupun jembatan dan biasanya di bangun dengan kontruksi beton bertulang.ada beberapa jenis pelat lantai yang sering di aplikasikan antara lain adalah pelat sederhana dengan tumpuan pada balok di setiap sisi-sisinya, pelat datar (flat slab) yang langsung bertumpu pada kolom, pelat waffe yang merupakan stuktur pelat komposit

Pada umumnya sistem penulangan pada pelat lantai masih menggunakan sistem-sistem beton bertulang non-prategang sejak di temukanya system penulangan prategang pada tahun 1928, penulangan prategang bayak di gunakan pada kontruksi beton sebagai pengganti tulangan utama pada gedung maupun jembatan penggunaan prategang pada kontruksi pelat lantai dapat menghilangkan kekurangan yang adalah utama pada perencanaan pelat adalah lendutan pada beton bertulang prategang.masalah lendutan dapat di atasi dengan menetukan besarannya gaya prategang,dengan pemberian prategang maka akan membatasi retak dan meningkatkan kekutan geser mengurangi tebal pelat yang di butuhkan

Untuk pembangunan gedung dengan kontruksi yang ringan, tipis tetapi kuat dalam perencanaan gedung lebih dari satu lantai adalah dengan membuat pelat beton yang ringan,tipis tetapi kuat dalam menahan beban stukturnya. Untuk menunjang hal tersebut di butuhkan suatu cara untuk meningkatkan kekuatan beton,khusunya kuat tekan,salah satu cara untuk meningkatkan kuat tekan beton .pelat beton bertulang merupakan bagian stuktur bangunan yang menahan beban permukaan(beban vertical), biasanya mempunyai arah horizontal, dengan permukaan atas dan bawahnya sejajar.

Tujuan yang diharapkan dari penelitian adalah untuk menghasilkan desain pelat lantai yang menggunakan konstruksi beton precast di evaluasi ke pelat lantai beton konvensional apakah sama tebal dari pelat precast ke tebal pelat konvensional maka dari itu di hitung dari ukuran tebal yang sama.

Objek dari penelitian ini adalah perencanaan Gedung Rusunawa Warudoyong Sukabumi Jawa 
Barat. Lokasi objek Tugas Akhir ini berada di Jalan lingkar Sukabumi Kelurahan Sukakarya Kecamatan Warudoyong Sukabumi.

Manfaat yang diharapkan dari penelitian ini adalah untuk menambah wawasan bagi peneliti mengenai pelat lantai yang di rubah dari pelat lantai precast ke pelat lantai konvensional dan juga memberi wawasan terhadap pembaca.

\section{TINJAUAN PUSTAKA}

a. Pengertian Pelat

Pelat atau slab adalah elemen bidang tipis yang menahan beban-beban tranpersal melalui aksi aksi lentur ke masing-masing tumpuan.

Teori-teori pertama tentang bangunan dengan lantai beton bertulang di turunkan berdasarkan asumsi yang identik dengan bangunan kayu.gayagaya struktur kayu di transmisikan dari lantai kayu ke balok anak balok induk dan balok kolom pada

b. Syarat-Syarat Tumpuan

Untuk merencanakan pelat beton bertulang yang perlu di pertimbangkan bukan hanya pembebanan tetapi juga ukuran dan syarat-syarat tumpuan pada tepi.Ada tiga jenis perletakan pada pelat yaitu :

1. Tertumpu bebas

2. Terjepit penuh/terjepit sempurna

3. Terjepit sebagian/terjepit elastis

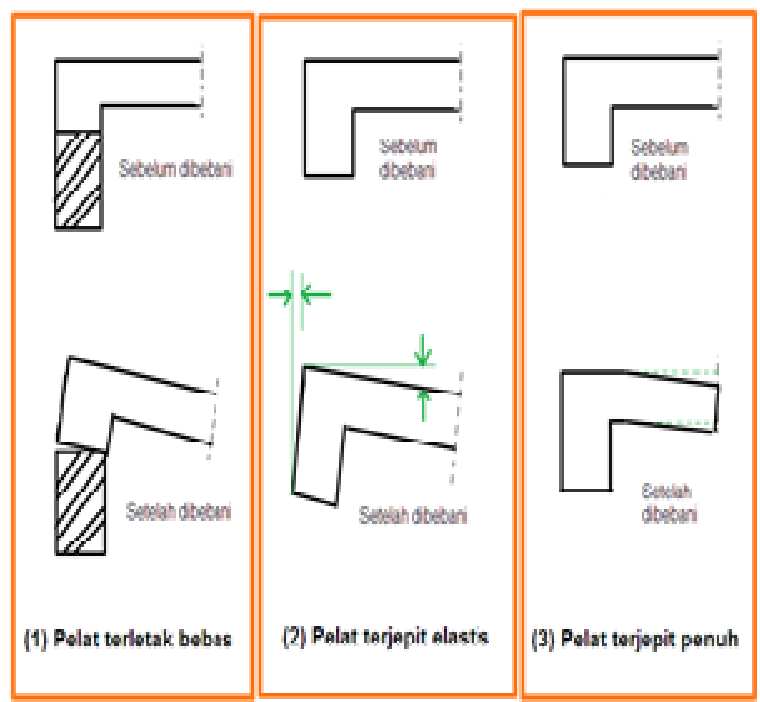

Gambar 2.1 jenis Perletakan Pada Pelat

\section{c. Tipe Pelat}

1. Sistem Flat Slab

Pelat beton bertulang yang langsung di tumpu oleh kolom kolom tanpa balok-balok di sebut system plat slab system ini di gunakan bila bentang tidak besar dan beban tidak terlalu berat,sperti bangunan apartemen atau hotel
Dan system bangunan ini bayak di guanakan rendah yang berisiko rendah terhadap beban angin dan gempa.

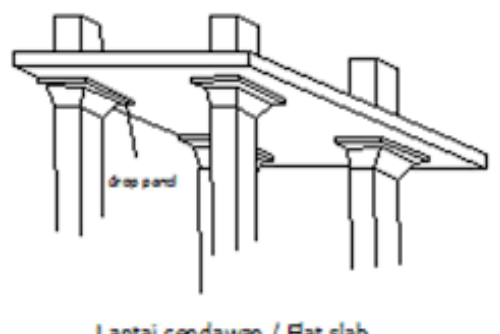

Gambar 2.2 Lantai Flat Slab

\section{Sistem Lantai Grid}

Sistem lantai grid dua arah memiliki balok-balok yang bersilangan dengan jarak yang relatif rapat yang menumpu pelat pelat atas yang tipis,ini di maksudkan untuk mengurangi beban sendiri pelat sistem ini efisien untuk bentang 9 hingga $12 \mathrm{~m}$.

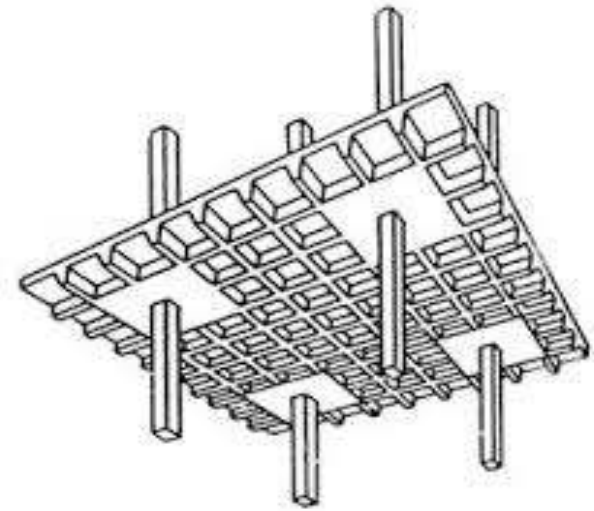

Gambar 2.3 sistem lantai grid

3. Sitem Pelat dan Balok

Sitem ini terdiri dari sleb menerus yang di tumputumpu balok-balok monolit yang umumnya di tempatkan pada jarak sumbu $3 \mathrm{~m}$ sampai $6 \mathrm{~m}$. tebal pelat di tempatkan berdasarkan stuktur yang biasa mencakup aspek keamanan terhadap bahaya kebakaran sistem ini yang bayak di pakai.

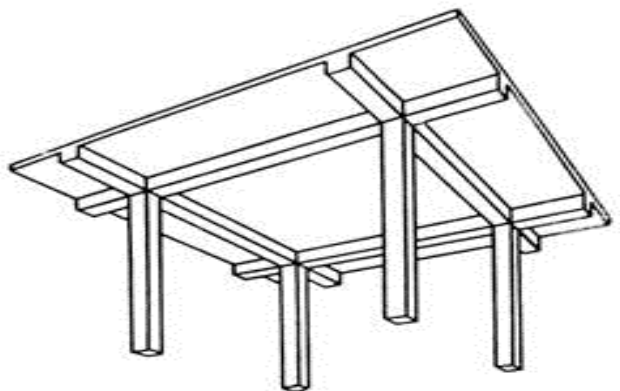

Gambar 2.4 Sistem Lantai Pelat dan Balok 


\section{d. Klasifikasi Pelat}

Pelat di klasifikasikan berdasarkan cara pelat tersebut di dukung. Dengan system pendukung tersebut,pelat akan melendut dalam satu arahatau dua arah ,pada pelat satu arah, biasanya pelat hanya di tumpu pada kedua sisi yang saling berhadapan.

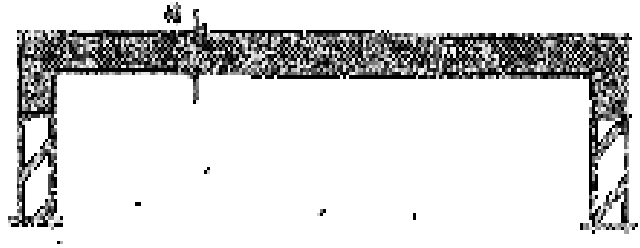

Gambar 2.5 Pelat satu arah

Pada pelat dua arah,pelat di tumpu pada kedua sisinya.Tetapi bila perbandingan antara sisi panjang (Ly) dan sisi pendek (Lx)lebih besar dari dua,maka pelat tersebut dapat di anggap sebagai pelat satu arah di mana beban pikul hanya di pikul dalam bentang pendek

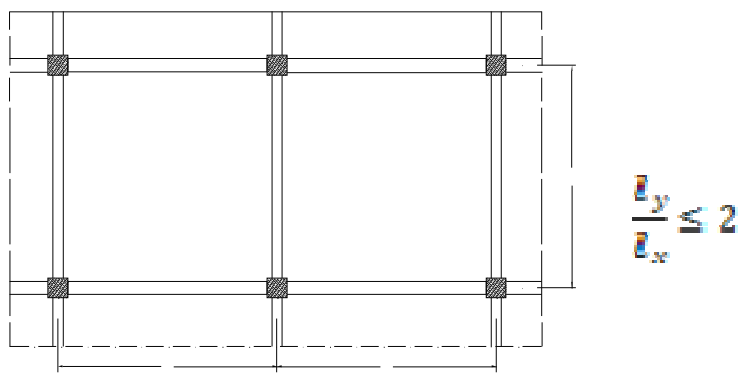

Gambar 2.6. Pelat dua arah

e. Pelat Satu Arah (One Way Slab)

Pelat Satu Arah adalah pelat beton bertulang yang mempunyai angka perbandingan antara bentang yang panjang dengan bentang yang pendek lebih besar atau sama dengan 3,0. Pada pelat satu arah, momen yang diperhitungkan dalam satu arah

Distribusi dgaya dalam pada pelat satu arah diatas $\mathrm{t}$ atau lebih tumpuan dapat di anggap sebagai balok di atas dua atau lebih tumpuan.Untuk stuktur statis tertentu besar reaksi perletakanya dapat di tentukan dengan persamaan perseimbngan statika $\sum \mathrm{H}=0 ; \sum \mathrm{V}=0 ; \sum \mathrm{H}=0$;

Untuk stuktur statis tak tentu, besar reaksi perletakanya dapat di tentukan dengan cara Clayperon,cara cross dan lain-lainya. Selain cara tersebut di atas

f. Pelat Dua Arah (Two Way Slab)

System berdasarkan kondisi tumpuanya, dapat melendut dalam dua arah pelat lantai/atap gedung,umunya mengunakan pelat dua arah,yang mana pelat tersebut di pikul oleh balok-balok dan atau kolom, maupun dinding yang tetaknya teratur sehingga panel panel pelatnya berbentuk empat persegi panjang.di tinjau dari segi pendudkungnya Sistem pelat dua arah di kelompokan menjadi dua yaitu :

1. Pelat dengan balok

2. Pelat tanpa balok

Pelat tanpa balok ada dua macam yaitu :

a) Di pikul langsung oleh kolom

b) Di pikul oleh kolom dengan kepala kolom atau penebalan pelat di sekitar b kolom.(flat slab)

pelat dengan balok di mana panel-panel pelatnya berbentuk empat persegi panjang, besarnya momen maksimum di tumpuan (Mtp) dan di lapangan (Mlap) pada kedua arah dapat ditentukan dengan menggunakan tabel-tabel yang tersedia dengan tebal pelat tetap yang ditumpu pada ketiga atau keempat sisinya dngan memperhatikan kondisi tumpuannya.

Bila panel-panel pelatnya tidak berbentuk persegi empat (tidak beraturan), besarnya Mtp dan Mlap pada kedua arah ditentukan dengan "metode garis leleh" (Yield Line Method). Bila terdapat lubang pada panel pelat berbentuk persegi empat, besarnya Mtp dan Mlap pada kedua arah ditentukan dengan "metode jalur" (Strip Method). Pembahasan pelat dua arah dikhususkan pada panel pelat yang berbentuk empat persegi panjang dengan tebal pelat tetap.

g. Perbedaan Antara Beton Pracetak dan Beton Konvensional

Pada dasarnya mendesain konvensional ataupun pracetak adalah sama, beban-beban yang diperhitungkan juga sama, faktor-faktor koefisien yang digunakan untuk perencanaan juga sama, hanya mungkin yang membedakan adalah :

1. Desain pracetak memperhitungkan kondisi pengangkatan beton saat umur beton belum mencapai 24 jam. Apakah dengan kondisi beton yang sangat muda saat diangkat akan terjadi retak (crack) atau tidak.Di sini dibutuhkan analisa desain tersendiri, dan tentunya tidak pernah diperhitungkan kalo kita menganalisa beton secara konvensional.

2. Desain pracetak memperhitungkan metode pengangkatan, penyimpanan beton pracetak di stock yard, pengiriman beton pracetak, dan pemasangan beton pracetak di proyek. beton pracetak dibuat di pabrik. 
3. Pada desain pracetak menambahkan desain sambungan. Desain sambungan di sini, didesain lebih kuat dari yang disambung.

\section{METODOLOGI PENELITIAN}

Dalam penelitian terdapat beberapa sumber data yaitu diantaranya adalah data primer dan data sekunder.

a. Data Primer

Data-data primer yaitu data yang didapatkan dari hasil survey langsung dilapangan, untuk mendapatkan data beton dan data gambar bangunan, Mutu beton K 350, Gambar bangunan gedung Rusunawa., Beban Hidup, Beban Mati b. Metode Analisa Metode Analisa data ini menggunakan SNI 032847-2002,20002. Tata Cara Perencanaan Stuktur Beton Untuk Bangunan Gedung, Badan Standarisasi Nasional.

Data yang di peroleh akan di analisis dengan menggunakan perhitungan dan perhitungan berdasarkan formula yang ada sehingga di dapat parameter nilai nilai yang sesuai dengan maksud penelitian.

\section{ANALISIS DATA}

Pada tahapan ini, akan menentukan dimensi elemen struktur pelat lantai. Tahapan ini diharapkan dapat memberikan dimensi pelat lantai yang efisien dan aman terhadap gaya yang bekerja pada struktur gedung.

\section{Pelat Lantai}

Tebal pelat yang direncanakan harus memiliki tebal yang sesuai dengan tebal minimum pelat sesuai dengan pasal 11.5.3.3 SNI 03-2847-2002. Pada pasal ini mengatur tentang tebal pelat berdasarkan perbandingan kekakukan rata-rata antara kekakuan balok dan kekakuan pelat Karena struktur beton dicor secara bersamaan.

Data Data Beton Precast

$\begin{array}{lll}\text { 1. } & \text { Mutu beton } & \text { : K } 350 \\ \text { 2. } & \text { Fy } & : 400 \mathrm{mpa} \\ \text { 3. } & \text { Sb } & : 40 \mathrm{~mm} \\ \text { 4. } & \text { H } & : 120 \mathrm{~mm} \\ \text { 5. } & \text { d } & : 70,5 \mathrm{~mm} \\ \text { 6. } & \text { L } & : 5400 \mathrm{~mm} \\ \text { 7. } & \text { D } & : 19 \mathrm{~mm} \\ \text { 8. } & \text { Qu } & : 9,92 \mathrm{kn} / \mathrm{m} 2\end{array}$

\section{Pelat lantai tipe A}

\begin{tabular}{|c|c|}
\hline $\mathrm{u}$ & $=9,92 \mathrm{KN} / \mathrm{m} 2$ \\
\hline & $=25 \mathrm{mpa}$ \\
\hline Fy & $=400 \mathrm{mpa}$ \\
\hline & $=40 \mathrm{~mm}$ \\
\hline ulangan utama $(\phi)$ & $=12 \mathrm{~mm}$ \\
\hline
\end{tabular}

$$
\begin{array}{ll}
\text { Hplat } & =150 \mathrm{~mm} \\
\mathrm{dx} & =104 \mathrm{~mm} \\
\mathrm{~b} & =1000 \mathrm{~mm}
\end{array}
$$

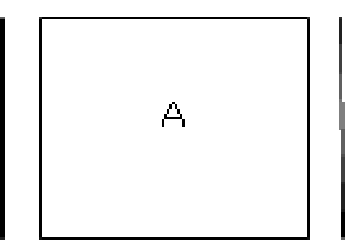

Gambar 3.1. Pelat Lantai tipe A

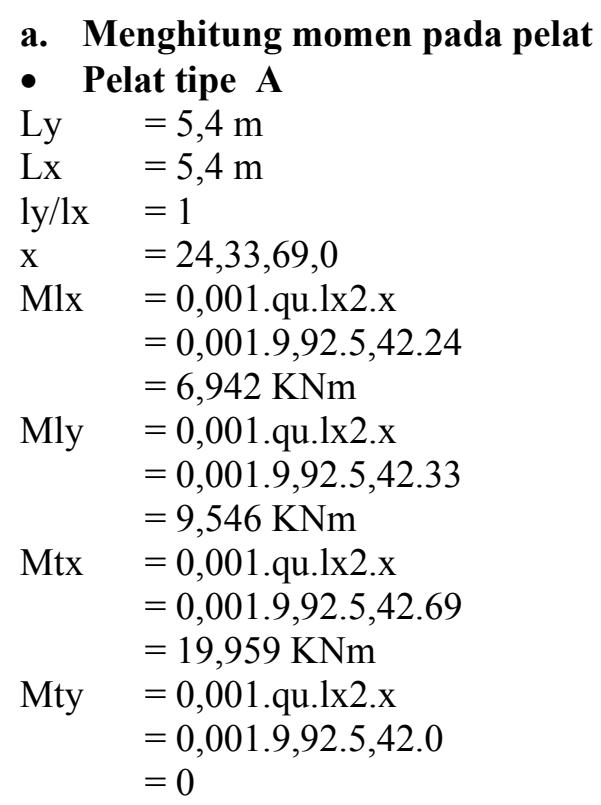

\section{- Tulangan lapangan}

$\mathrm{dx} \quad=\mathrm{h}-\mathrm{sb}-0,5 \phi$

$=150-40-6$

$=104 \mathrm{~mm}$

$\mathrm{Mu}=9,546 \mathrm{KNm}$

$\mathrm{Mn}=\mathrm{Mu} / 0,8$

$=9,546 / 0,8$

$=11,932 \mathrm{KNm}$

$\mathrm{Rn} \quad=\mathrm{Mn} /\left(\mathrm{b} . \mathrm{d}^{\wedge} 2\right)$

$=\llbracket\left(11,932 \cdot 10 \rrbracket^{\wedge} 6 /\left(1000 \cdot \llbracket\left(104 \rrbracket^{\wedge} 2\right)\right.\right.$

$=1,103$

$\mathrm{m} \quad=\mathrm{fy} / 0,85 \mathrm{fc}$

$=400 / 0,85.25$

$=18,823$

$\mathrm{p} \quad=1 / \mathrm{m}(1-\sqrt{ }(1-(2 \mathrm{Rn} . \mathrm{m}) / \mathrm{fy}))$

$=1 / 18,823(1-\sqrt{ }(1-2.1,103.18,823 / 400))$

$=0,00283$

$\operatorname{pmin}=1,4 /$ fy

$=1,4 / 400$

$=0,0035$

Asperlu $\quad=$ p.b.d

$$
=0,035.1000 .104
$$

$=364 \mathrm{~mm} 2$

As $\quad=0,25 \cdot \pi \cdot \mathrm{d} 2$ 


$$
\begin{aligned}
& =0,25 \cdot \pi \cdot 122 \\
& =113,04 \mathrm{~mm} 2
\end{aligned}
$$

$$
\begin{aligned}
\mathrm{N} \text { tulangan } & =\text { Asperlu/As } \phi 12 \\
& =364 / 113,04 \\
& =3,22 \text { buah } \sim 4 \text { buah per } 1 \text { meter }
\end{aligned}
$$

Jarak tulangan $(\mathrm{S}) \quad=1000 /(\mathrm{n}-1)$

$$
=1000 /(4-1)
$$$$
=358,45 \mathrm{~mm}
$$

Maka diambil jarak tulangan yaitu $350 \mathrm{~mm}$ per 1 meter

\section{- Pengecekan}

$$
\begin{aligned}
& \begin{array}{ll}
\text { As } \quad=\text { As } \phi 12 . n \\
= & 113,04.4 \\
& =452,16 \mathrm{~mm} 2
\end{array} \\
& \text { Asperlu } \quad=364 \mathrm{~mm} 2 \\
& \begin{aligned}
\text { As }>\text { Asperlu (ok) aman } \\
\text { Pada } \quad=\text { As/(b.d) } \\
=452,16 / 1000.104 \\
=0,0043
\end{aligned}
\end{aligned}
$$

Pmin $<$ pada (ok aman)

Kontrol spasi maksimum

Jarak maksimal $=3 . \mathrm{h}$

$$
\begin{aligned}
& =3.150 \\
& =450 \mathrm{~mm}
\end{aligned}
$$

Jarak tulangan $(\mathrm{S})<$ jarak maksimal (Smaksimal) (Ok aman) Maka dipakai 4ф12-350.

\section{b. Tulangan Tumpuan}

$$
\begin{aligned}
\mathrm{dx} & =\mathrm{h}-\mathrm{sb}-0,5 \phi \\
& =150-40-6 \\
& =104 \mathrm{~mm} \\
\mathrm{Mu} & =19,959 \mathrm{KNm} \\
\mathrm{Mn} & =\mathrm{Mu} / 0,8 \\
& =19,959 / 0,8 \\
& =24,948 \mathrm{KNm} \\
\mathrm{Rn} & =\mathrm{Mn} /\left(\mathrm{b} \cdot \mathrm{d}^{\wedge} 2\right) \\
& \left.=[24,948 \cdot 10]^{\wedge} 6 /(1000 \cdot(104)]^{\wedge} 2\right) \\
& =2,306 \\
& =\mathrm{fy} / 0,85 \mathrm{fc} \\
& =400 / 0,85 \cdot 25 \\
& =18,823 \\
\mathrm{p} & =1 / \mathrm{m}(1-\sqrt{ }(1-(2 \mathrm{Rn} \cdot \mathrm{m}) / \mathrm{fy})) \\
& =1 / 18,823(1-\sqrt{ }(1-2 \cdot 2,306.18,823 / 400)) \\
\mathrm{pmin} & =0,0061 \\
& =1,4 / \mathrm{fy} \\
& =0,0035
\end{aligned}
$$

Asperlu $\quad=$ p.b.d

$$
=0,0061.1000 .104
$$$$
=636,095 \mathrm{~mm} 2
$$

As $=0,25 \cdot \pi \cdot \mathrm{d} 2$

$=0,25 \cdot \pi \cdot 122$

$=113,04 \mathrm{~mm} 2$

$\mathrm{N}$ tulangan $\quad=$ Asperlu/As $\phi 12$

$$
=636,095 / 113,04
$$

$=5,627$ buah $\sim 6$ buah per 1 meter

Jarak tulangan $(\mathrm{S}) \quad=1000 /(\mathrm{n}-1)$

$=1000 /(6-1)$

$=200 \mathrm{~mm}$

Maka diambil jarak tulangan yaitu $200 \mathrm{~mm}$ per 1 meter.

\section{- Pengecekan}

$$
\begin{aligned}
& \text { As } \quad \text { As } \phi 12 . n \\
& =113,04.6 \\
& =678,24 \mathrm{~mm} 2 \\
& \text { Asperlu }=636,095 \mathrm{~mm} 2 \\
& \text { As }>\text { Asperlu (ok) aman } \\
& \text { Pada }=\text { As } /(\text { b.d) } \\
& =678,24 / 1000.104 \\
& =0,0065 \\
& =3.150 \\
& =450 \mathrm{~mm}
\end{aligned}
$$

Jarak tulangan $(\mathrm{S})<$ jarak maksimal (Smaksimal) (Ok aman) Maka dipakai 6ф12-200.

\section{Pelat lantai Tipe $B$}

$\mathrm{Qu}=9,92 \mathrm{KN} / \mathrm{m} 2$

$\mathrm{Fc}=25 \mathrm{mpa}$

Fy $=400 \mathrm{mpa}$

$$
\rho \quad=40 \mathrm{~mm}
$$

$$
\begin{array}{ll}
\text { Tulangan utama }(\phi) & =12 \mathrm{~mm} \\
\text { Hplat } & =150 \mathrm{~mm} \\
\mathrm{dx} & =104 \mathrm{~mm} \\
& =1000 \mathrm{~mm}
\end{array}
$$

B

Gambar 3.2. Pelat Lantai tipe B

\section{a. Menghitung momen pada pelat}

\section{- Pelat tipe B}

Ly $\quad=5,4 \mathrm{~m}$

$\mathrm{Lx} \quad=5,4 \mathrm{~m}$

$\mathrm{ly} / \mathrm{lx}=1$

$\mathrm{x} \quad=24,33,69,0$

Mlx =0,001.qu.lx2.x

$=0,001.9,92.5,42.33$

$=9,546 \mathrm{KNm}$

Mly $=0,001$.qu. $1 x 2 . x$

$=0,001 \cdot 9,92.5,42.24$

$=6,942 \mathrm{KNm}$ 


$$
\begin{aligned}
\text { Mtx } & =0,001 \cdot q u \cdot 1 x 2 \cdot \mathrm{x} \\
& =0,001 \cdot 9,92 \cdot 5,42 \cdot 69 \\
& =19,959 \mathrm{KNm} \\
\text { Mty } & =0,001 \cdot q u \cdot 1 \times 2 \cdot \mathrm{x} \\
& =0,001 \cdot 9,92 \cdot 5,42 \cdot 0 \\
& =0
\end{aligned}
$$

\section{- Tulangan lapangan}

$$
\begin{aligned}
& \mathrm{dx} \quad=\mathrm{h}-\mathrm{sb}-0,5 \phi \\
& =150-40-6 \\
& =104 \mathrm{~mm} \\
& \mathrm{Mu} \quad=9,546 \mathrm{KNm} \\
& \mathrm{Mn} \quad=\mathrm{Mu} / 0,8 \\
& =9,546 / 0,8 \\
& =11,932 \mathrm{KNm} \\
& \mathrm{Rn}=\mathrm{Mn} /\left(\mathrm{b} . \mathrm{d}^{\wedge} 2\right) \\
& =\llbracket\left(11,932 \cdot 10 \rrbracket^{\wedge} 6 /\left(1000 \cdot \llbracket 104 \rrbracket^{\wedge} 2\right)\right. \\
& =1,103 \\
& \mathrm{~m} \quad=\mathrm{fy} / 0,85 \mathrm{fc} \\
& =400 / 0,85.25 \\
& =18,823 \\
& \mathrm{p} \quad=1 / \mathrm{m}(1-\sqrt{ }(1-(2 \mathrm{Rn} \cdot \mathrm{m}) / \mathrm{fy})) \\
& =1 / 18,823(1-\sqrt{ }(1-2.1,103.18,823 / 400)) \\
& =0,00283 \\
& \text { pmin } \quad=1,4 / \mathrm{fy} \\
& =1,4 / 400 \\
& =0,0035 \\
& \text { Asperlu } \quad=\text { p.b.d } \\
& =0,035 \cdot 1000 \cdot 104 \\
& =364 \mathrm{~mm} 2 \\
& \text { Asperlu } \quad=0,25 . \pi \cdot \mathrm{d} 2 \\
& =0,25 \cdot \pi \cdot 122 \\
& =113,04 \mathrm{~mm} 2 \\
& \mathrm{~N} \text { tulangan }=\text { Asperlu/As } \phi 12 \\
& =364 / 113,04 \\
& =3,22 \text { buah } \sim 4 \text { buah per } 1 \text { meter }
\end{aligned}
$$

Jarak tulangan $(\mathrm{S}) \quad=1000 /(\mathrm{n}-1)$

$$
=1000 /(4-1)
$$$$
=358,45 \mathrm{~mm}
$$

Maka diambil jarak tulangan yaitu $350 \mathrm{~mm}$ per 1 meter

\section{- Pengecekan}

$$
\begin{aligned}
& \text { As } \quad=\text { As } \phi 12 . \mathrm{n} \\
& \quad=113,04.4 \\
& \quad=452,16 \mathrm{~mm} 2 \\
& \text { Asperlu } \quad=364 \mathrm{~mm} 2 \\
& \begin{aligned}
\text { As }>\text { Asperlu (ok) aman } \\
\text { Pada } \quad \text { As/(b.d) } \\
\quad=452,16 / 1000.104 \\
=0,0043
\end{aligned}
\end{aligned}
$$

Pmin $<$ pada (ok aman)

Kontrol spasi maksimum

Jarak maksimal $=3 . \mathrm{h}$

$$
\begin{aligned}
& =3.150 \\
& =450 \mathrm{~mm}
\end{aligned}
$$

Jarak tulangan $(\mathrm{S})<$ jarak maksimal (Smaksimal) (Ok aman) Maka dipakai 4\$12-350

\section{- Tulangan Tumpuan}

$$
\begin{aligned}
\mathrm{dx} & =\mathrm{h}-\mathrm{sb}-0,5 \phi \\
& =150-40-6 \\
& =104 \mathrm{~mm} \\
\mathrm{Mu} & =19,959 \mathrm{KNm} \\
\mathrm{Mn} \quad & =\mathrm{Mu} / 0,8 \\
& =19,959 / 0,8 \\
& =24,948 \mathrm{KNm} \\
\mathrm{Rn} \quad & =\mathrm{Mn} /\left(\mathrm{b} \cdot \mathrm{d}^{\wedge} 2\right) \\
& =\left[24,948 \cdot 10 \rrbracket^{\wedge} 6 /\left(1000 \cdot\left[104 \rrbracket^{\wedge} 2\right)\right.\right. \\
& =2,306 \\
& =\mathrm{fy} / 0,85 \mathrm{fc} \\
& =400 / 0,85 \cdot 25 \\
& =18,823 \\
& =1 / \mathrm{m}(1-\sqrt{ }(1-(2 \mathrm{Rn} \cdot \mathrm{m}) / \mathrm{fy})) \\
& =1 / 18,823(1-\sqrt{ }(1-2.2,306 \cdot 18,823 / 400)) \\
& =0,0061 \\
\mathrm{pmin} & =1,4 / \mathrm{fy} \\
& =1,4 / 400 \\
& =0,0035
\end{aligned}
$$

Asperlu $\quad=$ p.b.d $=636,095 \mathrm{~mm} 2$

$$
\begin{aligned}
& \text { As } \quad=0,25 . \pi \cdot \mathrm{d} 2 \\
& =0,25 \cdot \pi \cdot 122 \\
& =113,04 \mathrm{~mm} 2 \\
& \mathrm{~N} \text { tulangan }=\text { Asperlu/As } \phi 12 \\
& =636,095 / 113,04 \\
& =5,627 \text { buah } \sim 6 \text { buah per } 1 \text { meter } \\
& \text { Jarak tulangan }(\mathrm{S}) \quad=1000 /(\mathrm{n}-1) \\
& =1000 /(6-1) \\
& =200 \mathrm{~mm}
\end{aligned}
$$

Maka diambil jarak tulangan yaitu $200 \mathrm{~mm}$ per 1 meter.

\section{- Pengecekan}

$$
\begin{aligned}
& \text { As }=\text { As } \phi 12 . n \\
& =113,04.6 \\
& =678,24 \mathrm{~mm} 2 \\
& \text { Asperlu }=636,095 \mathrm{~mm} 2 \\
& \text { As }>\text { Asperlu (ok) aman } \\
& \begin{aligned}
\text { Pada } & =\text { As } /(\text { b.d }) \\
& =678,24 / 1000.104 \\
& =0,0065
\end{aligned} \\
& =3.150 \\
& =450 \mathrm{~mm}
\end{aligned}
$$

Jarak tulangan $(\mathrm{S})<$ jarak maksimal (Smaksimal) (Ok aman) Maka dipakai 6\$12-200 


\section{Pelat lantai Tipe $C$}

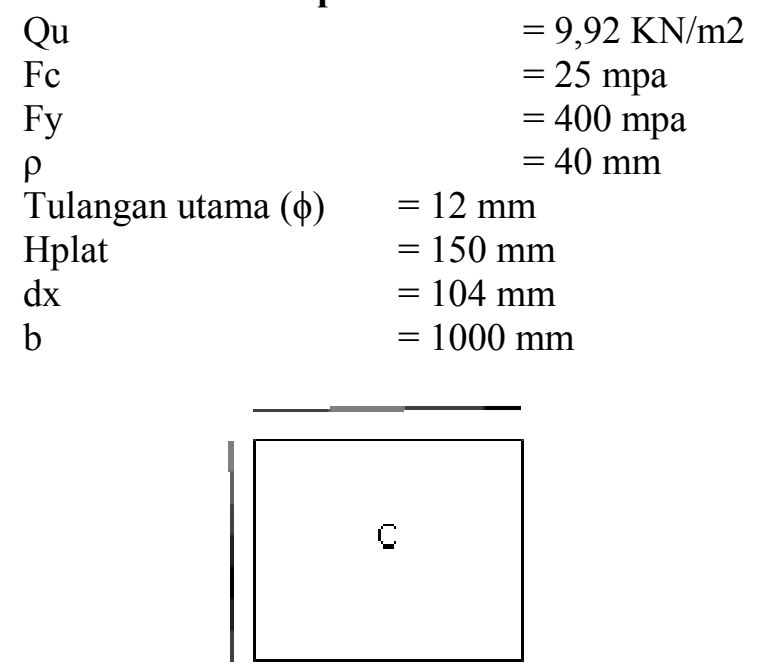

Gambar 3.3. Pelat Lantai tipe B

$$
\begin{aligned}
& \text { a. Menghitung momen pada pelat } \\
& \text { - Pelat tipe C } \\
& \text { Ly }=5,4 \mathrm{~m} \\
& \mathrm{Lx}=5,4 \mathrm{~m} \\
& 1 \mathrm{y} / \mathrm{lx} \quad=1 \\
& \mathrm{x} \quad=24,33,69,0 \\
& \text { Mlx }=0,001 \cdot q u \cdot l x 2 \cdot x \\
& =0,001 \cdot 9,92 \cdot 5,42.30 \\
& =8,68 \mathrm{KNm} \\
& \text { Mly } \quad=0,001 \cdot q u \cdot 1 \times 2 \cdot x \\
& =0,001 \cdot 9,92 \cdot 5,42 \cdot 30 \\
& =8,68 \mathrm{KNm} \\
& \text { Mtx }=0,001 \cdot q u \cdot 1 \times 2 \cdot x \\
& =0,001.9,92.5,42.68 \\
& =19,67 \mathrm{KNm} \\
& \text { Mty }=0,001 \cdot q u \cdot 1 \times 2 \cdot x \\
& =0,001.9,92.5,42.68 \\
& =19,67 \mathrm{KNm}
\end{aligned}
$$

- Tulangan lapangan

$$
\begin{aligned}
\mathrm{dx} & =\mathrm{h}-\mathrm{sb}-0,5 \phi \\
& =150-40-6 \\
& =104 \mathrm{~mm} \\
\mathrm{Mu} & =8,68 \mathrm{KNm} \\
\mathrm{Mn} & =\mathrm{Mu} / 0,8 \\
& =8,68 / 0,8 \\
& =10,85 \mathrm{KNm} \\
\mathrm{Rn} \quad & =\mathrm{Mn} /\left(\mathrm{b} \cdot \mathrm{d}^{\wedge} 2\right) \\
& =\llbracket 10,85 \cdot 10 \rrbracket^{\wedge} 6 /\left(1000 \cdot\left[104 \rrbracket^{\wedge} 2\right)\right. \\
\mathrm{m} \quad & =1,003 \\
& =\mathrm{fy} / 0,85 \mathrm{fc} \\
& =400 / 0,85 \cdot 25 \\
\mathrm{p} \quad & =18,823 \\
& =1 / \mathrm{m}(1-\sqrt{ }(1-(2 \mathrm{Rn} \cdot \mathrm{m}) / \mathrm{fy})) \\
& =1 / 18,823(1-\sqrt{ }(1-2 \cdot 1,003 \cdot 18,823 / 400)) \\
& =0,0025
\end{aligned}
$$

$$
\begin{aligned}
\operatorname{pmin} & =1,4 / \mathrm{fy} \\
& =1,4 / 400 \\
& =0,0035
\end{aligned}
$$

Asperlu $\quad=$ p.b.d

$$
=0,035 \cdot 1000 \cdot 104
$$

As $\quad=0,25 . \pi \cdot \mathrm{d} 2$

$$
=364 \mathrm{~mm} 2
$$

$=0,25 \cdot \pi \cdot 122$

$=113,04 \mathrm{~mm} 2$

$\mathrm{N}$ tulangan $=$ Asperlu/As $\phi 12$

$$
=364 / 113,04
$$$$
=3,22 \text { buah } \sim 4 \text { buah per } 1 \text { meter }
$$

Jarak tulangan $(\mathrm{S})$

$$
\begin{aligned}
(\mathrm{S}) & =1000 /(\mathrm{n}-1) \\
& =1000 /(4-1)
\end{aligned}
$$$$
=358,45 \mathrm{~mm}
$$

Maka diambil jarak tulangan yaitu $350 \mathrm{~mm}$ per 1 meter

\section{- Pengecekan}

$$
\begin{aligned}
& \text { As } \quad=\text { As } \phi 12 . n \\
& =113,04.4 \\
& =452,16 \mathrm{~mm} 2 \\
& \text { Asperlu }=364 \mathrm{~mm} 2 \\
& \text { As }>\text { Asperlu (ok) aman } \\
& \text { Pada }=\text { As } /(\text { b.d }) \\
& =452,16 / 1000.104 \\
& =0,0043
\end{aligned}
$$

Pmin < pada (ok aman) Kontrol spasi maksimum Jarak maksimal

$$
\begin{aligned}
& =3 . \mathrm{h} \\
& =3.150 \\
& =450 \mathrm{~mm}
\end{aligned}
$$

Jarak tulangan $(\mathrm{S})<$ jarak maksimal (Smaksimal) (Ok aman) Maka dipakai 4\$12-350

$$
\begin{aligned}
& \text { - Tulangan Tumpuan } \\
& \mathrm{dx} \quad=\mathrm{h} \text {-sb- } 0,5 \phi \\
& =150-40-6 \\
& =104 \mathrm{~mm} \\
& \mathrm{Mu} \quad=19,67 \mathrm{KNm} \\
& \mathrm{Mn}=\mathrm{Mu} / 0,8 \\
& =19,67 / 0,8 \\
& =24,6 \mathrm{KNm} \\
& \mathrm{Rn}=\mathrm{Mn} /\left(\mathrm{b} . \mathrm{d}^{\wedge} 2\right) \\
& =\llbracket\left(24,6.10 \rrbracket^{\wedge} 6 /\left(1000 \cdot \llbracket\left(104 \rrbracket^{\wedge} 2\right)\right.\right. \\
& =2,273 \\
& \mathrm{~m} \quad=\mathrm{fy} / 0,85 \mathrm{fc} \\
& =400 / 0,85.25 \\
& =18,823 \\
& \mathrm{p} \quad=1 / \mathrm{m}(1-\sqrt{ }(1-(2 \mathrm{Rn} . \mathrm{m}) / \mathrm{fy})) \\
& =1 / 18,823(1-\sqrt{ }(1-2.2,273.18,823 / 400)) \\
& =0,0060 \\
& \operatorname{pmin}=1,4 / \mathrm{fy} \\
& =1,4 / 400 \\
& =0,0035 \\
& =0,0060 \cdot 1000 \cdot 104
\end{aligned}
$$




$$
\begin{aligned}
& =626,74 \mathrm{~mm} 2 \\
\text { As } & =0,25 \cdot \pi \cdot \mathrm{d} 2 \\
& =0,25 \cdot \pi \cdot 122 \\
& =113,04 \mathrm{~mm} 2
\end{aligned}
$$

$\mathrm{N}$ tulangan $\quad=$ Asperlu/As $\phi 12$

$=626,74 / 113,04$

$=5,54$ buah $\sim 6$ buah per 1 meter

Jarak tulangan $(\mathrm{S}) \quad=1000 /(\mathrm{n}-1)$

$=1000 /(6-1)$

$=200 \mathrm{~mm}$

Maka diambil jarak tulangan yaitu $200 \mathrm{~mm}$ per 1 meter

\section{- Pengecekan}

As $\quad=$ As $\phi 12 . n$

$$
=113,04.6
$$$$
=678,24 \mathrm{~mm} 2
$$

Asperlu $=626,74 \mathrm{~mm} 2$

As $>$ Asperlu (ok) aman

Pada $\quad=$ As $/($ b.d $)$

$$
=678,24 / 1000.104
$$$$
=0,0065
$$

Pmin $<$ pada (ok aman) Kontrol spasi maksimum Jarak maksimal

$$
\begin{aligned}
& =3 . \mathrm{h} \\
& =3.150 \\
& =450 \mathrm{~mm}
\end{aligned}
$$

Jarak tulangan $(\mathrm{S})<$ jarak maksimal (Smaksimal) (Ok aman), Maka dipakai 6\$12-200

Maka dari perhitungan perbandingan kekuatan antara beton precast dengan beton konvensional yaitu :

\section{- Data beton precat dilapangan :}

$\begin{array}{ll}\text { Mutu beton } & : \text { K350 } \\ \text { Fy } & : 400 \mathrm{mpa} \\ \mathrm{Sb} & : 40 \mathrm{~mm} \\ \mathrm{H} & : 120 \mathrm{~mm} \\ \mathrm{~d} & : 70,5 \mathrm{~mm} \\ \mathrm{~L} & : 5400 \mathrm{~mm} \\ \mathrm{D} & : 19 \mathrm{~mm} \\ \mathrm{Wu} & : 9,92 \mathrm{KN} / \mathrm{m} 2\end{array}$

- Data beton konvensional :

Mutu beton (fc) : $25 \mathrm{mpa}$

$\begin{array}{ll}\text { Fy } & : 400 \mathrm{mpa} \\ \mathrm{Sb} & : 40 \mathrm{~mm} \\ \mathrm{H} & : 150 \mathrm{~mm} \\ \mathrm{~d} & : 104 \mathrm{~mm} \\ \mathrm{~L} & : 5400 \mathrm{~mm} \\ \phi & : 12 \mathrm{~mm} \\ \mathrm{Wu} & : 9,92 \mathrm{KN} / \mathrm{m} 2\end{array}$

\section{KESIMPULAN}

Dari hasil pembahasan dapat di ambil kesimpulan pelat beton bertulang merupakan bagian stuktur bangunan yang menahan bebab permukaan,pelat dapat di tumpu oleh,balok beton bertulang dinding pasangan batu atau dinding beton bertulang batang-batang stuktur baja di tumpu oleh kolom atau stuktur tanah.dalam pembahasan tugas akhir ini penulis melakukan evaluasi antara pelat beton precast dan pelat beton konvensional.

Di tinjau dari perbedaan stuktur beton pelat lantai yang menggunakan pelat precast,dan pelat konvensional.

Dapat di simpulkan bahwa dari data yang ada pada pelat precast di evaluasi ke pelat konvensional ternyata hasil dari pembahasan di hasilkan pelat lantai sama kuat dan aman yang membedakan Cuma dari pengerjaan pelat lantai tersebut.

\section{DAFTAR PUSTAKA}

Freeckheinz Ilmu Kontruksi bangunan 2 (1980), Yogyakarta:kanisius

SNI 03-2847-2002,20002. Tata Cara Perencanaan StukturBeton Untuk Bangunan Gedung, Badan Standarisasi Nasional.

Kusuma ,I,K,S,.Perbandingan Biaya Pelaksanaan Pekerjaan Struktur Beton Dengan Metode Konvensional dan Precast, Tugas Akhir 2006,Program Studi Teknik sipil Fakultas Teknik Universitas Udayana. 